\title{
The refractometry of the uniaxially stressed ferroelectrics
}

\author{
M.O.Romanyuk, V.Yo.Stadnyk \\ The Ivan Franko State University of Lviv, \\ 8 Kyryla and Mefodiya Str., 79005 Lviv, Ukraine \\ Received March 1, 1999, in final form October 14, 1999
}

The effect of uniaxial mechanical stresses upon the spectral and temperature dependences of birefringences in some ferroelectric crystals with the incommensurate phase are studied. Considerable baric displacements of para-incommensurate-commensurate phases transition points were observed.The calculated temperature and spectral dependences of combined $\pi_{i m}^{0}$ and absolute $\pi_{i m}$ piezooptic constants show a considerable dispersion and anomalies at phase transitions. The increase of the principal refractive indices under stress effect was observed.

Key words: ferroelectrics, phase transition, optical properties, refractive indices, birefringence, piezooptic constants

PACS: 77.80.Bh, 77.84.Fa, 78.20.Ci

\section{Introduction}

Many works are devoted to the investigation of baric changes of optical properties of crystals [1]. Piezooptic constants of few crystals were determined, and the birefringence sign inversion of some mechanically stressed cubic crystals was observed. It was shown that some piezooptic constants nonlinearly vary in the region of ferroelectric phase transition [2-5]. High sensibility of incommensurate phase to uniaxial stress was observed $[6,7]$. In the present paper the results of piesooptic investigations of several ferroelectrics ( $\mathrm{LiKSO}_{4}$ (LPS), $\left(\mathrm{NH}_{4}\right)_{2} \mathrm{BeF}_{4}(\mathrm{AFB}), \quad \mathrm{RbNH}_{4} \mathrm{SO}_{4}$ (RAS), $\mathrm{KNaC}_{4} \mathrm{H}_{4} \mathrm{O}_{6} \cdot 4 \mathrm{H}_{2} \mathrm{O}(\mathrm{RS}), \mathrm{KH}_{2} \mathrm{PO}_{4}(\mathrm{KDP})$ and $\left.\mathrm{KD}_{2} \mathrm{PO}_{4}(\mathrm{DKDP})\right)$ are presented. These crystals possess the phase transitions (PT) and birefringence sign inversion (BSI) $[8-12]$ in a wide temperature region $(4.2 \div 1000) \mathrm{K}$.

The purpose of this paper is to study the effect of uniaxial mechanical stresses along the principal crystallophysic directions and bisectors between them upon the spectral and temperature dependences of birefringence, baric displacements of PT points, as well as to determine the temperature and spectral changes of piezooptic constants in the above enumerated crystals. 


\section{Experiment}

The effect of uniaxial mechanical stresses upon the birefringent properties of crystals are studied by the changes of interference picture. The birefringence is calculated using the formula:

$$
\left.\Delta n_{i}(\lambda, T)\right|_{\sigma}=\frac{k(T) \lambda}{d_{i}(T, \sigma)},\left.\quad \Delta n_{i}(\lambda, \sigma)\right|_{T}=\frac{k(\sigma) \lambda}{d_{i}(T, \sigma)}
$$

where the markers used are known.

The measurements are carried out up to the pressure of $\sigma_{m} \sim 200$ bar and temperature decreasing. The samples were stressed at room temperature. The KDP crystals were stressed along the normal to symmetry plane of paraphase. These directions were preliminaryly determined by the interference figures pattern of biaxial crystals. These figures were obtained when the electric field $E_{z}$ was applied to the crystal at room temperature. The combined difference of piezooptic constants is determined using the formula:

$$
\pi_{i m}^{0}=\frac{2 \delta \Delta n_{i}}{\sigma_{m}}+2 \Delta n_{i} s_{i m}
$$

where $\delta \Delta n_{i}$ is the induced change of birefringence for the $i$-direction of light propagation; $\sigma_{m}$ is the mechanical pressure along the $m$-direction; $i$ and $m$ are the crystallophysic axes; $s_{i m}$ are the elastic complince coefficients.

\section{Results and discussion}

It was determined, that the birefringence of crystals is sensitive enough to uniaxial stress along the principal crystallophysic directions and is less sensitive to stress along the bisectors between them (figure 1).

\subsection{Uniaxial stress effects the birefringence of crystals}

The following regularity is observed: uniaxial stresses along the mutually perpendicular crystallophysic directions lead to the opposite signs of birefringence changes (see table 1).

As a rule, the birefringence of all crystals studied becomes more sensitive to stress effect at the decrease of wavelength. The baric sensibility of $\Delta n_{i}$ increases at approaching the BSI point.

\subsection{Baric displacement of PT points}

The following regularity of baric displacement of PT points are studied (see table 2). The uniaxial stresses $\sigma_{x}$ and $\sigma_{y}$ lead to expanding the incommensurate phase (IP) of AFB crystal and to the displacement of temperature range of its occurence to the low temperature region. The uniaxial stress $\sigma_{z}$ leads to the narrowing of the IP. It was determined by $T_{i, c}(\sigma)$ extrapolation that the IP disappears and the PT 


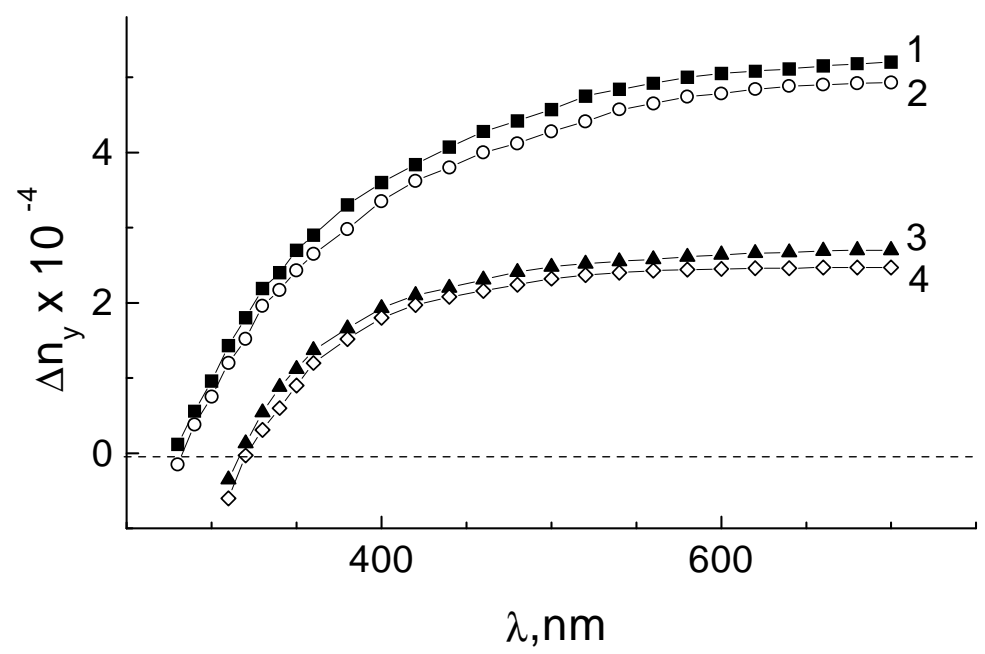

Figure 1. Birefringence dispersion for $\mathrm{LiKSO}_{4}$ crystal: $1-T=294 \mathrm{~K}, \sigma=150$ bar; $2-T=294 \mathrm{~K}, \sigma=0$ bar; $3-T=226 \mathrm{~K}, \sigma=100$ bar; $4-T=226 \mathrm{~K}, \sigma=0$ bar.

Table 1. Baric changes of birefringence of crystals at room temperature

\begin{tabular}{|c|c|c|c|c|}
\hline pressure & $\Delta n_{x}$ & $\Delta n_{y}$ & $\Delta n_{z}$ & crystal \\
\hline \hline $\mathrm{X}$ & - & increase & increase & \\
\hline $\mathrm{Y}$ & decrease & - & decrease & $\left(\mathrm{NH}_{4}\right)_{2} \mathrm{BeF}_{4}$ \\
\hline $\mathrm{Z}$ & increase & decrease & - & \\
\hline $\mathrm{X}$ & - & decrease & decrease & \\
\hline $\mathrm{Y}$ & decrease & - & increase & Rochelle salt \\
\hline $\mathrm{Z}$ & increase & increase & - & \\
\hline \hline $\mathrm{X}$ & - & increase & decrease & \\
\hline $\mathrm{Y}$ & increase & - & decrease & $\mathrm{RbNH}_{4} \mathrm{SO}_{4}$ \\
\hline $\mathrm{Z}$ & decrease & decrease & - & \\
\hline \hline $\mathrm{X}$ & - & decrease & - & \\
\hline $\mathrm{Y}$ & - & - & - & $\mathrm{LiKSO}_{4}$ \\
\hline $\mathrm{Z}$ & - & increase & - & \\
\hline \hline $\mathrm{X}$ & - & increase & - & \\
\hline $\mathrm{Y}$ & - & - & - & $\mathrm{KH}_{2} \mathrm{PO}_{4}$ \\
\hline $\mathrm{Z}$ & - & decrease & - & \\
\hline \hline $\mathrm{X}$ & - & increase & - & \\
\hline $\mathrm{Y}$ & - & - & - & $\mathrm{KD}_{2} \mathrm{PO}_{4}$ \\
\hline $\mathrm{Z}$ & - & decrease & - & \\
\hline
\end{tabular}


of paraphase-commensurate phase ("triple point") takes place at $\sigma_{z} \sim 2.3 \mathrm{kbar}$ and $T \sim 190 \mathrm{~K}$. The "triple point" of LPS crystal takes place at $\sigma_{z} \sim 4.3 \mathrm{kbar}$ and $T \sim 286 \mathrm{~K}$.

The PT points are very sensitive to uniaxial stress action along the principal crystallophysic directions. The summary effect of the whole component $\sigma_{m}$ leads to the displasement of PT points to the low temperature region (figure 2).

Table 2. The temperature-baric coefficients of PT point displacement

\begin{tabular}{|c|c|c|c|c|}
\hline pres. & $\mathrm{d} T_{i} / \mathrm{d} \sigma_{m}, \mathrm{~K} / \mathrm{bar}$ & $\mathrm{d} T_{c} / d \sigma_{m}, \mathrm{~K} / \mathrm{bar}$ & $\sum \mathrm{d} T / \mathrm{d} \sigma_{m}, \mathrm{~K} / \mathrm{bar}$ & crystal \\
\hline \hline $\mathrm{X}$ & - & $-0,017$ & - & \\
\hline $\mathrm{Y}$ & - & $-0,013$ & $-0,015$ & $\mathrm{RbNH}_{4} \mathrm{SO}_{4}$ \\
\hline $\mathrm{Z}$ & - & 0,015 & - & \\
\hline \hline $\mathrm{X}$ & $-0,32$ & $-0,021$ & - & \\
\hline $\mathrm{Y}$ & $-0,045$ & $-0,107$ & $-0,007\left(T_{i}\right)$ & $\mathrm{LiKSO}_{4}$ \\
\hline $\mathrm{Z}$ & 0,070 & 0,120 & $-0,008\left(T_{c}\right)$ & \\
\hline \hline $\mathrm{X}$ & - & $-0,003$ & - & \\
\hline $\mathrm{Y}$ & - & 0,008 & $-0,007$ & $\mathrm{KH}_{2} \mathrm{PO}_{4}$ \\
\hline $\mathrm{Z}$ & - & $-0,007$ & - & \\
\hline \hline $\mathrm{X}$ & - & $-0,007$ & - & \\
\hline $\mathrm{Y}$ & - & 0,011 & $-0,008$ & $\mathrm{KD}_{2} \mathrm{PO}_{4}$ \\
\hline $\mathrm{Z}$ & - & $-0,012$ & - & \\
\hline \hline $\mathrm{X}$ & $-0,011$ & $-0,016$ & - & \\
\hline $\mathrm{Y}$ & $-0,009$ & $-0,012$ & $-0,017\left(T_{i}\right)$ & $\left(\mathrm{NH}_{4}\right)_{2} \mathrm{BeF}_{4}$ \\
\hline $\mathrm{Z}$ & 0,003 & 0,005 & $-0,023\left(T_{c}\right)$ & \\
\hline
\end{tabular}

The baric dependences of PT points are caused by the uniaxial stress effect upon crystal structure, mainly, due to the change of position and orientation of $\mathrm{BeF}_{4}^{2-}$, $\mathrm{SO}_{4}^{2-}$, and $\mathrm{PO}_{4}^{2}-$ basic tetrahedral groups.

\subsection{The piezooptic properties of crystals}

Using the experimental dependences $\Delta n_{i}(\lambda, T, \sigma)$ the temperature and spectral dependences of piezooptic constants $\pi_{i m}^{0}$ were calculated using the formula (2).

The significant dispersion of $\pi_{i m}^{0}\left(\left|d \pi_{i m}^{0}\right| / d \lambda<0\right)$ was observed (figure 3$)$. The anomalies of $\pi_{i m}^{0}(T)$ in the region of PT agree with the anomalous changes of $n_{i}(T)$ and $\Delta n_{i}(T)$. The crossing of the curves $\pi_{i m}^{0}(\lambda)$ in the region of BSI was determined (index $i$ denotes the direction of isotropic point appearing), which testifies to the rising of symmetry of the fourth order piezooptic constants tensor.

Using the experimental results and the known formula for piezobirefringence of orthorhombic crystals (Pokkel's method [1]) we have calculated temperature and spectral dependences of absolute piezooptic constants of AFB, RAS and RS crystals 


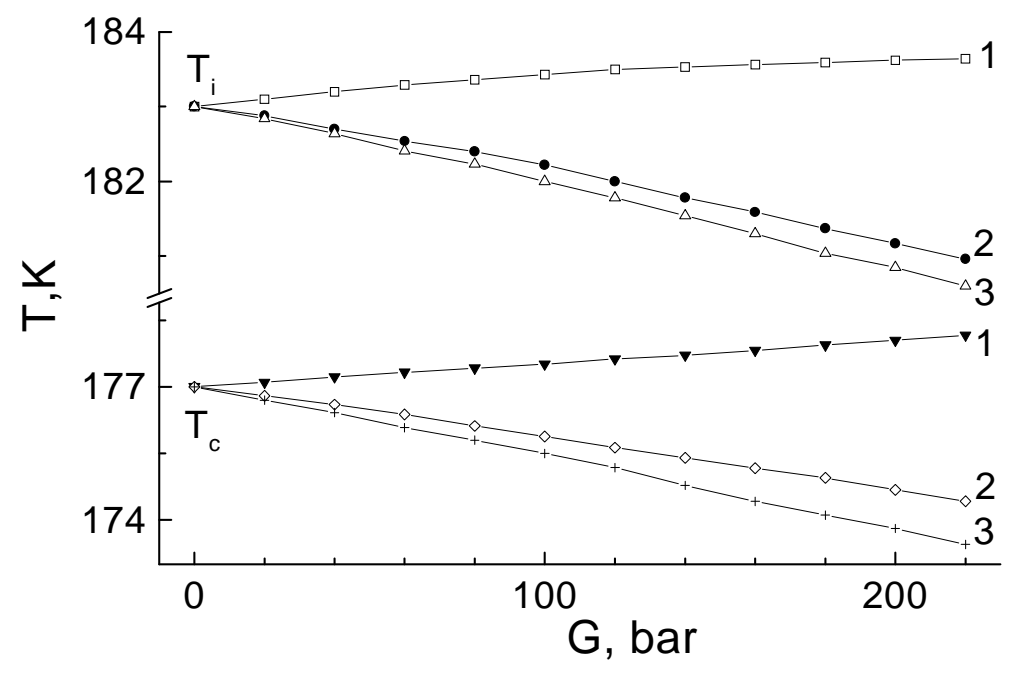

Figure 2. Baric dependence of phase transition points for $\left(\mathrm{NH}_{4}\right)_{2} \mathrm{BeF}_{4}$ crystal: 1 $-\sigma_{z} ; 2-\sigma_{y} ; 3-\sigma_{x}$

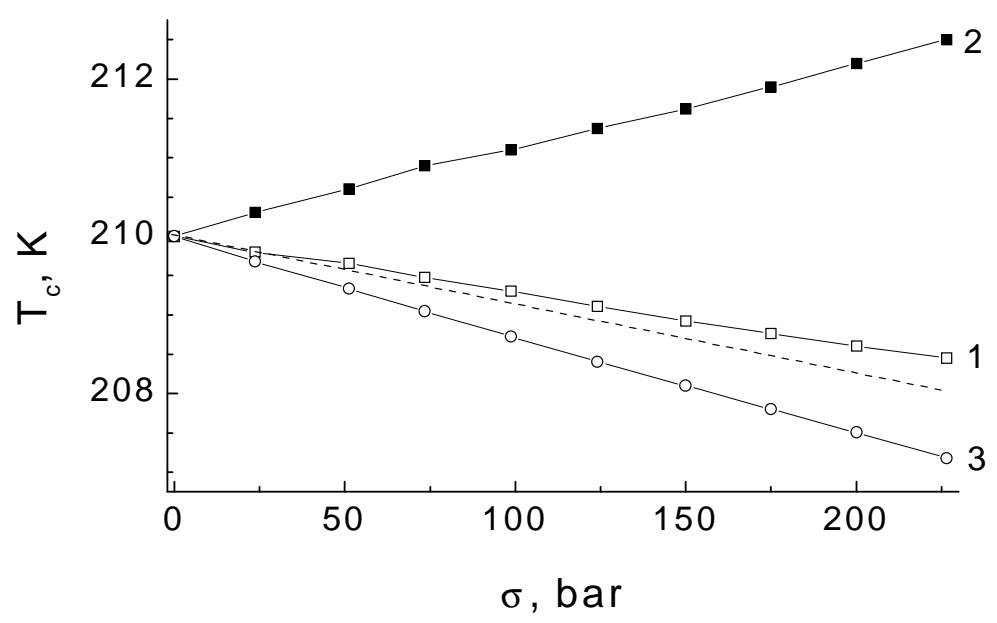

Figure 3. Baric dependence of the phase transition point for KDP crystal: 1 $\sigma_{y} ; 2-\sigma_{x} ; 3-\sigma_{z}$ 
(figure 4) by solving the following system of equations:

$$
\mathrm{d} \Delta n_{i m}=1 / 2\left(n_{m}^{3} \pi_{m m}-n_{k}^{3} \pi_{k m}\right)
$$

where $i, k, m=1,2,3 ; \mathrm{d} \Delta n_{i m}$ are the induced changes of birefringence for $i$-th direction of light polarization and $m$-th direction of pressure action; $n_{m}, n_{k}$ are the known refractive indices of the mechanically unstressed crystal.

It was established that the rising of $\left|d \pi_{i m}^{0}\right|$ modulus is caused by the nearness of edge fundamental absorption (it's in the ultraviolet region for all crystals studied) as well as by its displacement under the uniaxial stress effect.

\subsection{The refractive indices of mechanically stressed crystals}

The analysis of baric changes of the principal refractive indices was carried out using the calculated piezooptic constants by the formula:

$$
n_{i}(\lambda, T)=n_{i 0}(\lambda, T)-1 / 2\left(\pi_{i m}(\lambda, T) \sigma_{m} n_{i 0}^{3}(\lambda, T)\right),
$$

where $n_{i 0}$ is the refractive index of the mechanically unstressed crystal.

On the whole, the $n_{i}$ values of crystals studied increase at the uniaxial stress effect. The uniaxial stress does not vary the character of the behaviour of $n_{i}(\lambda)$ and $n_{i}(T)$ dependences (figure 5 ).

The electron polarizability $\alpha$ and molar refraction $R_{i}$ of the crystals studied for light propagation along $\mathrm{X}, \mathrm{Y}, \mathrm{Z}$-directions were calculated using the spectral dependences $n_{i}(\lambda, \sigma)$ by the formula:

$$
\left(n_{i}^{2}-1\right) /\left(n_{i}^{2}+2\right)=4 / 3 \pi N_{0} \alpha_{i}=\rho R_{i} / \mu .
$$

It was determined that bonds refraction and the electron polarizability increase under the uniaxial stress effect. Obviously, the uniaxial stress varies the degree of ordering of the crystal structure, which is manifested in increasing the electron polarizability. In our case, the changes of bonds refraction and electron polarizability lead to the changes of the electron subsystem of the crystal, determining the character of interaction of the environment and the electromagnetic light wave.

Using the dependences $n_{i}(\lambda, \sigma)$, the ultraviolet $\left(\lambda_{0 i}, B_{i}\right)$ and the infrared $\left(B_{i}^{\prime}\right)$ oscillator parameters were calculated by Zelmeer's formula:

$$
n_{i}^{2}-1=\frac{B_{i} \lambda_{0 i}^{2} \lambda^{2}}{\lambda^{2}-\lambda_{0 i}^{2}}-B_{i}^{\prime} \lambda^{2}
$$

It was established for AFB, RS and RAS crystals that the uniaxial stress displaces the position of an effective center of UV absorption band mainly to the long wave region: $\mathrm{d} \lambda_{0} / \mathrm{d} \sigma_{m} \sim(4 \ldots 8) \cdot 10^{-3} \mathrm{~nm} /$ bar. The increase of absolute refractive indices $n_{i}$ is caused by the decrement of the effective strength of UV oscillators and by the displacement of the effective center of UV absorption band to the long wave region. Higher sensibility of the dependence $n_{i}(T)$ to stress effect was observed in the region of IP for AFB crystal. It is caused, to our mind, by the peculiarities of interaction between the modulated structure and the uniaxial deformation. 


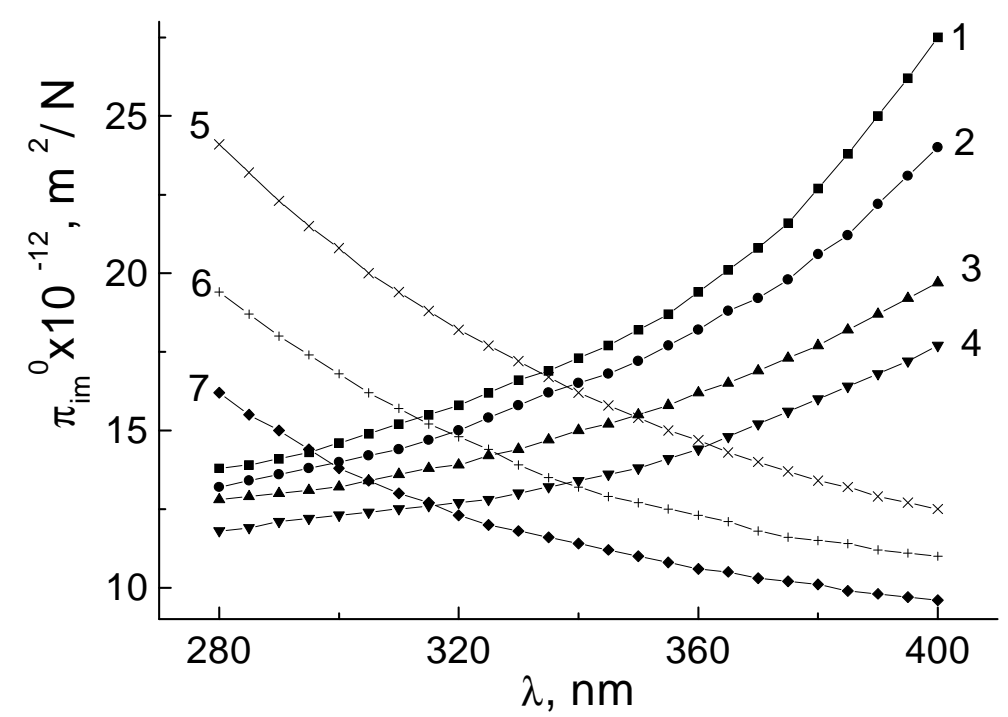

Figure 4. Dispersion of the combined piezooptic constants for $\mathrm{LiKSO}_{4}$ crystal: $1-294 \mathrm{~K}, 2-260 \mathrm{~K}, 3-230 \mathrm{~K}, 4-190 \mathrm{~K}\left(\pi_{13}^{0}\right) ; 5-294 \mathrm{~K}, 6-260 \mathrm{~K}, 7-190 \mathrm{~K}$ $\left(\pi_{12}^{0}\right)$.

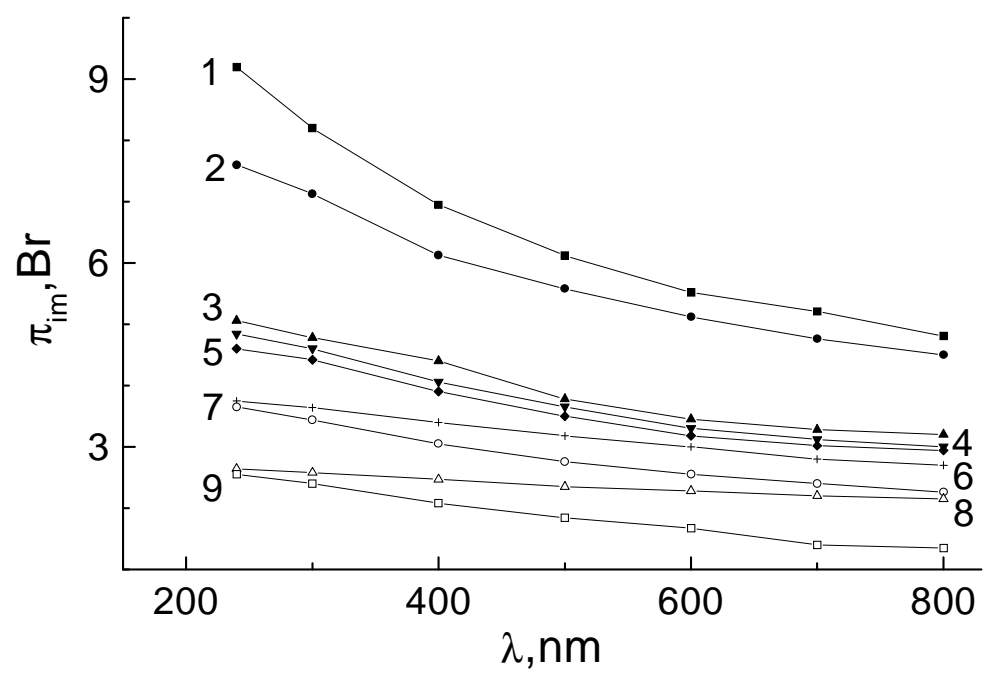

Figure 5. Dispersions of the absolute piezooptic constants for Rochelle salts crystal at room temperature: $1-\pi_{21}, 2-\pi_{31}, 3-\pi_{12}, 4-\pi_{11}, 5-\pi_{32}, 6-\pi_{13}, 7-$ $\pi_{22}, 8-\pi_{23}, 9-\pi_{33}$. 


\subsection{The temperature-spectral-baric diagram of the isotropic state}

It was determined that the uniaxial stress along the mutually perpendicular crystallophysic directions, normally to the direction of BSI, displaces the point of BSI to the opposite spectral regions at a constant temperature and to the opposite temperature regions at a constant wavelength. The temperature-spectral-baric diagram of isotropic state for AFB, LPS, RS and RAS crystals was constructed. It enables us to determine singlevaluedly the BSI point for definite temperature and spectral interval at the stress effect up to $\sigma_{m} \sim 200$ bar as well as to propose the possible usage of these crystals as crystallooptic sensors of temperature and pressure, simultaneously.

\section{Conclusion}

1. The birefringence $\Delta n_{i}$ is relatively sensitive to the uniaxial mechanical stress along the principal crystallophysic directions $k$ and $m$ and is less sensitive along the bisectors of these directions. The common regularity was observed, that the stresses along the mutually perpendicular crystallophysic directions $k$ and $m$ lead to the opposite by sign values of changes of $\Delta n_{i}$.

2. A considerable baric displacement of para-incommensurate-commensurate phases PT points and Curie points was observed. The "triple point" of disappearing of IP under the action of $\sigma_{x}$ and $\sigma_{y}$ was observed for LPS and AFB crystals.

3. The calculated temperature and spectral dependences of combined $\pi_{i m}^{0}$ and absolute $\pi_{i m}$ piezooptic constants show a considerable dispersion (mainly $\frac{\left|\mathrm{d} \pi_{i m}^{0}\right|}{\mathrm{d} \lambda}<$ 0 ) and anomalies at PTs, that agree with the changes of $n_{i}$ and $\Delta n_{i}$ at PTs. In the region of BSI the crossing of $\pi_{i m}(\lambda, T)$ curves was observed for all the crystals studied. This fact testifies to the rising of symmetry of the piezooptic tensor or to the lowering of its anisotropy.

4. The increase of principal refractive indices under stress effect was observed, which is caused by the increase of bonds refraction and electron polarizability. A uniaxial stress mainly decreases an effective strength of UV oscillators and displaces an effective center of UV absorption band to the long wave region. The refractive indices become more sensitive to the pressure action in the region of the IP.

5. The temperature-spectral-baric diagrams of the isotropic state of the crystals studied have been constructed. 


\section{References}

1. Narasimhamurty T.S. Photoelastic and electro-optic properties of crystals. New-York and London, Plenum Press, 1981.

2. Romanyuk N.A., Mytsyk B.G., Varikash V.M. The piezooptic properties of triglicine sulphate crystals. // Izv. AN BSSR, ser. fiz.-mat. nauk, 1980, No. 6, p. 105-110 (in Russian).

3. Romanyuk N.A., Mytsyk B.G., Kulyk L.M. The piezochanges of optical properties of triglicine sulphate crystals. // Ukr. Fiz. Zh., 1986, vol. 31, No. 3, p. 354-359 (in Russian).

4. Mytsyk B.G., Romanyuk N.A. The temperature dependences of piezooptic coefficients of diglicine nitrate crystals. // Ukr. Fiz. Zh., 1983, vol. 28, No. 4, p. 538-542 (in Russian).

5. Romanyuk N.A., Mytsyk B.G., Varikash V.M. The piezooptic properties of triglicine crystals. // Fiz. Tverd. Tela, 1983, vol. 25, No. 6, p. 1670-1674 (in Russian).

6. Vlokh O.G., Polovynko I.I., Mokryj V.M. Birefringence and piezooptic properties $\left[\mathrm{N}\left(\mathrm{CH}_{3}\right)_{4}\right]_{2} \mathrm{FeCl}_{4}$ crystals. // Ukr. Fiz. Zh., 1990, vol. 45, No. 3, p. 349-353 (in Russian).

7. Vlokh O.G., Kapustyanyk V.B., Mokryj V.M. Piezooptic effect and phase diagram of incommensurate $\left[\mathrm{N}\left(\mathrm{CH}_{3}\right)_{4}\right]_{2} \mathrm{MnCl}_{4}$ crystals. // Izv. vuzov, 1990, No. 7, p. 92-94 (in Russian).

8. Aleksandrov K.S., Beznosikov V.B. Structural phase transitions in crystals $\left(\beta-\mathrm{K}_{2} \mathrm{SO}_{4}\right.$ group). Nauka Publ., Novosibirsk, 1984 (in Russian).

9. Stadnyk V.Y., Gaba V.M., Romanyuk N.A. About of isotropic point in $\mathrm{LiKSO}_{4}$ crystals. // Optika i Spektr., 1990, vol. 68, No. 3, p. 701-703 (in Russian).

10. Romanyuk M.O., Stadnyk V.Y., Brezvin R.S. The influence of pressure on optical properties of $\mathrm{LiKSO}_{4}$ crystals. // Ukr. Fiz. Zh., 1995, vol. 40, No. 10, p. 1068-1070 (in Ukrainian).

11. Romanyuk N.A., Gaba V.M., Ursul Z.M. The character of optical properties anisotropy of ammonium fluoroberyllate crystals in isotropic point. - In: "Optics of anisotropic media" (interdepartment collection), Physics-and-Technical Institute Publ., Moscow, 1987, p. 105-107 (in Russian).

12. Gaba V.M., Ursul Z.M., Romanyuk N.A. The pecularities of optical indicatrix symmetry of ammonium fluoroberyllate crystals in region 4.2-420 K. // Kristallografiya, 1989, vol. 34, No. 4, p. 1038-1040 (in Russian). 


\title{
Рефрактометрія механічно затиснутих сегнетоелектриків
}

\author{
М.О.Романюк, В.Й.Стадник
}

Львівський державний університет ім. І.Франка, 79005 Львів, вул. Кирила і Мефодія, 8

Отримано 1 березня 1999 р., в остаточному вигляді 14 жовтня 1999 р.

Досліджено вплив одновісного механічного тиску на температурні і спектральні зміни двозаломлення, баричні зміни точок фазових переходів, температурно-спектральні залежності п'єзооптичних констант, а також проаналізовано температурні, спектральні та баричні зміщення точок інверсії знаку двозаломлення деяких сегнетоелектричних кристалів, що володіють несумірною фазою. Виявлено значні баричні зміщення точок фазових переходів параелектричнанесумірна-сумірна фази. Виявлено значну дисперсію та аномалії при фазових переходах у поведінці комбінованих $\pi_{i m}^{0}$ та абсолютних $\pi_{i m}$ п'єзооптичних констант. Встановлено, що головні показники заломлення зростають при дії одновісного тиску, що зумовлено збільшенням рефракцій зв'язку та електронної поляризованості. Побудовано температурно-спектрально-баричні діаграми ізотропного стану.

Ключові слова: сегнетоелектрики, фазові переходи, оптичні властивості, показники заломлення, двозаломлення, п'єзооптичні константи

PACS: $77.80 \mathrm{Bh}, 77.84 \mathrm{Fa}, 78.20 \mathrm{Ci}$ 